\title{
PENINGKATAN UTILISASI JARINGAN DISTRIBUTED STORAGE SYSTEM MENGGUNAKAN KOMBINASI SERVER DAN LINK LOAD BALANCING
}

\author{
Hawwin Purnama Akbar ${ }^{* 1}$, Achmad Basuki², Eko Setiawan ${ }^{3}$ \\ 1,2,3 Fakultas Ilmu Komputer, Universitas Brawijaya \\ Email: 1haw2win@student.ub.ac.id, ${ }^{2}$ abazh@ub.ac.id, ${ }^{3}$ ekosetiawan@ub.ac.id \\ ${ }^{*}$ Penulis Korespondensi
}

(Naskah masuk: 04 November 2021, diterima untuk diterbitkan: 09 Juni 2021)

\begin{abstract}
Abstrak
Distributed Storage System (DSS) memiliki sejumlah perangkat server penyimpanan yang terhubung dengan banyak perangkat switch untuk meningkatkan utilisasi jaringan. DSS harus memperhatikan keseimbangan beban pada sisi server penyimpanan dan traffic data pada semua jalur yang terhubung. Jika beban pada sisi server penyimpanan dan traffic data tidak seimbang, maka dapat menyebabkan bottleneck network yang menurunkan utilisasi jaringan. Kombinasi server dan link load balancing adalah solusi yang tepat untuk menyeimbangkan beban pada sisi server penyimpanan dan traffic data. Penelitian ini mengusulkan metode kombinasi algoritme least connection sebagai metode server-load balancing dan algoritme global first fit sebagai metode link load balancing. Algoritme global first fit merupakan salah satu dari algoritme load balancing hedera yang bertujuan untuk menyeimbangkan traffic data berukuran besar $(10 \%$ dari bandwidth), sehingga terhindar dari permasalahan bottleneck network. Algoritme least connection merupakan salah satu algoritme server load balancing yang menggunakan jumlah total koneksi dari server untuk menentukan prioritas server. Hasil evaluasi kombinasi metode tersebut didapatkan peningkatan pada rata-rata throughput sebesar 77,9\% dibanding hasil metode Equal Cost Multi Path (ECMP) dan Round robin (RR). Peningkatan pada rata-rata penggunaan bandwidth sebesar 65,2\% dibanding hasil metode ECMP dan RR. Hasil Penggunaan CPU dan memory pada server di metode kombinasi ini juga terjadi penurunan beban $C P U$ sebesar 34,29\% dan penurunan beban penggunaan memory sebesar 9,8\% dibanding metode ECMP dan RR. Dari hasil evaluasi, penerapan metode kombinasi metode server dan link load balancing berhasil meningkatkan utilisasi jaringan dan juga mengurangi beban server.
\end{abstract}

Kata kunci: DSS, Load balancing, bottleneck network

\section{IMPROVEMENT OF DISTRIBUTED STORAGE SYSTEM NETWORK UTILIZATION USING COMBINATION OF SERVER AND LINK LOAD BALANCING}

\begin{abstract}
Distributed Storage System (DSS) has a number of storage server devices that are connected to multiple switch devices to increase network utilization. DSS must pay attention to the balance of the load on the storage server side and data traffic on all connected lines. If the load on the storage server side and data traffic is not balanced, it can cause a network bottleneck that reduces network utilization. The combination of server and link-load balancing is the right solution to balance the load on the server side of storage and data traffic. This study proposes a combination of the least connection algorithm as a server-load balancing method and the global first fit algorithm as a link-load balancing method. The global first fit algorithm is one of Hedera's load balancing algorithms which aims to balance large data traffic (10\% of bandwidth), so as to avoid network bottleneck problems. Least connection algorithm is one of the server balancing algorithms that uses the total number of connections from the server to determine server priority. The results of the evaluation of the combination of these methods showed an increase in the average throughput of $77.9 \%$ compared to the results of the Equal Cost Multi Path (ECMP) and Round robin (RR) methods. The increase in the average bandwidth usage is $65.2 \%$ compared to the results of the ECMP and RR methods. The results of CPU and memory usage on the server in this combination method also decreased CPU load by $34.29 \%$ and a decrease in memory usage load by $9.8 \%$ compared to the ECMP and RR methods. From the evaluation results, the application of a combination of the server method and the link load balancing method has succeeded in increasing network utilization and also reducing server load.
\end{abstract}

Keywords: DSS, Load balancing, bottleneck network 


\section{PENDAHULUAN}

Survey kondisi cloud server tahun 2020 dari flexera menyatakan $93 \%$ dari perusahaan enterprise besar dengan jumlah pegawai diatas 1000 sudah mengadopsi sistem cloud computing (Flexera, 2020). Jaringan data center dalam skala besar dibutuhkan untuk mendukung perkembangan layanan cloud tersebut. Arsitektur data center memiliki subsistem yaitu jaringan Distributed Storage System (DSS). DSS dapat menyediakan tempat penyimpanan secara terdistribusi menjadi beberapa tiruan atau copy dan ditempatkan pada node yang berbeda dalam jaringan (Liu dkk., 2015). Jaringan dengan skala besar dengan topologi berjenis multi-layer dibutuhkan untuk peningkatan utilisasi jaringan DSS dengan efektif. Pada jaringan multi-layer juga terdapat sebuah masalah untuk mengatur dan menjadwalkan lalu lintas data pada jalur yang terdapat dalam jaringan (Guillen dkk., 2018b). Salah satu solusi untuk untuk mengatur dan menjadwalkan lalu lintas data adalah dengan mendistribusikan lalu lintas data secara seimbang di semua jalur yang ada.

Agar lalu lintas data dapat didistribusikan secara seimbang, terdapat mekanisme load balancing. Mekanisme load balancing bertujuan untuk membagi secara rata flow dari berbagai jalur yang berbeda (Zhang dkk., 2018). Tujuan umum dari mekanisme load balancing yaitu, 1) meningkatkan kinerja, 2) robustness, 3) skalabilitas, dan 4) energy-efficiency. Peningkatan kinerja jaringan dapat dilakukan dengan mekanisme load balancing yang dapat dibagi menjadi dua berdasarkan targetnya yaitu link load balancing untuk mengatur lalu lintas data pada traffic data dan server load balancing untuk mengatur lalu lintas data pada server penyimpanan (Zhang dkk., 2018). Untuk mengaplikasikan mekanisme load balancing dibutuhkan pendekatan Software Defined Network (SDN) dengan openflow switch agar dapat memprogram lalu lintas data dalam jaringan. SDN adalah arsitektur jaringan yang memisahkan fungsi control plane dan data plane dari switch, sehingga dapat memprogram fungsi control plane dari semua perangkat dengan satu controller saja (Xia dkk., 2018) (Kreutz dkk., 2015).

Terdapat penelitian yang membahas tentang penggunaan link load balancing dengan menggunakan sebuah metode bernama Hedera (AlFares dkk., 2010). dalam metode hedera terdapat algoritme Global First Fit yaitu algoritme pasif dan terpusat yang bertujuan untuk mengatur dan menyeimbangkan flow yang berukuran besar $(>10 \%$ dari ukuran bandwidth) sehingga dapat menghindari terjadinya bottleneck network. Bottleneck network yaitu suatu fenomena saat kinerja atau kapasitas sistem dibatasi oleh keterbatasan suatu komponen. Kinerja Algoritme Global First Fit telah dibandingkan dengan Algoritme Equal Cost Multi Path (ECMP) yang merupakan algoritme dasar dari link load balancing, hasil dari perbandingan menunjukkan algoritme Global First Fit dapat membagi rata beban ke semua jalur yang tersedia dan mengungguli kinerja dari algoritme ECMP, tetapi algoritme ini masih belum membagi rata beban pada sisi server atau storage jika digunakan pada jaringan DSS.

Penelitian terkait algoritme server load balancing adalah algoritme least loaded server (Chen dkk., 2014). Algoritme ini mengatur beban server dengan parameter beban yang dimiliki server atau dengan metode least loaded, semakin sedikit beban pada server, maka semakin besar prioritas server untuk dipilih. Untuk mengetahui beban yang dimiliki server, algoritme ini menggunakan informasi yang diperoleh dari protokol Simple Network Management Protocol (SNMP). Penelitian Chen hanya menggunakan satu jalur yang menghubungkan host dengan berbagai server, sehingga tidak memperhitungkan jaringan dengan jalur lebih dari satu seperti pada jaringan DSS. Terdapat algoritme least connection yang juga merupakan algoritme server load balancing. Algoritme least connection menggunakan parameter total koneksi yang ada pada setiap server untuk menentukan prioritas server. Terdapat penelitian yang telah membandingkan algoritme least connection dan least loaded oleh Mustafa (Mustafa, 2017) yang menyatakan algoritme least connection dapat mendistribusikan lalu lintas pada server dengan lebih baik dibanding algoritme least loaded server dan round-robin.

Penelitian terkait lainnya yaitu kombinasi mekanisme link load balancing dan server load balancing (Guillen dkk., 2018a). Penelitian tersebut mengimplementasikan kombinasi algoritme Max Disjoint Path untuk link load balancing dan Least Loaded Server untuk server load balancing pada arsitektur jaringan DSS. Guillen menggunakan jaringan data center dengan model fat tree network (FTN) sebagai studi kasus dari DSS. Penelitian yang dilakukan berhasil mengimplementasikan kombinasi mekanisme load balancing dengan hasil yang melebihi hingga $150 \%$ nilai rata-rata throughput dibanding mekanisme load balancing tunggal. Kekurangan dari penelitian ini yaitu eksperimen yang dilakukan hanya menggunakan flow dengan ukuran kecil dengan rata-rata penggunaan bandwidth sebesar $6.5 \%$ dari kapasitas bandwidth yang disediakan. Meskipun flow dikirim dengan waktu yang panjang, tidak akan memenuhi kapasitas jalur yang disediakan dan tidak memperhatikan terjadinya collision atau tabrakan data yang dapat menyebabkan bottleneck network.

Berdasarkan penjelasan sebelumnya, maka ditemukan permasalahan baru yaitu dapat terjadinya collision yang dapat menyebabkan bottleneck network pada mekanisme kombinasi load balancing, sehingga dapat dikembangkan lagi untuk meningkatkan utilisasi jaringan DSS. Oleh karena itu penelitian ini mengusulkan kombinasi server dan 
link load balancing berbasis SDN untuk meningkatkan utilisasi jaringan DSS secara optimal. Link load balancing menggunakan algoritme Global first fit yang dikombinasikan dengan server load balancing menggunakan algoritme least connection. Hasil penelitian dianalisis berdasarkan throughput, bandwidth, CPU usage, dan memory usage.

\section{METODE PENELITIAN}

\subsection{Arsitektur Sistem}

Metode kombinasi load balancing link dan server diajukan untuk menangani permasalahan pada DSS. Pada arsitektur sistem terdapat tiga komponen utama yang mengendalikan perilaku switch yang terhubung dalam jaringan seperti pada Gambar 1 . Komponen pertama yaitu load balancing module yang terdiri dari algoritme global first fit dan algoritme least connection, komponen kedua yaitu routing module yaitu modul untuk menentukan jalur terpendek antara host dan server yang dituju dari semua jalur yang tersedia. Routing module ini menggunakan algoritme Dijkstra untuk menemukan path terdekat dan juga berfungsi mengoleksi informasi dari jalur yang dibutuhkan oleh algoritme load balancing. Komponen ketiga yaitu flow scheduler yang berfungsi untuk menempatkan jalur yang telah ditentukan oleh algoritme load balancing ke jalur dalam jaringan agar bisa dilalui flow yang akan dikirim. Agar dapat menguji flow dengan ukuran besar, akan menggunakan kapasitas jalur pada topologi sebesar $1 \mathrm{GbE}$ pada semua jalur yang menghubungkan switch dan host.

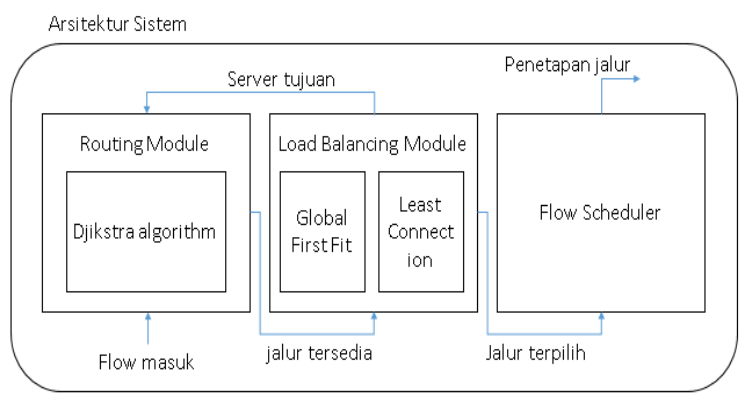

Gambar 1. Arsitektur Sistem

Untuk topologi jaringan, akan digunakan topologi dari DCN berjenis FTN dengan jumlah host $=8$ seperti pada Gambar 2. terdapat 4 node yang berperan sebagai host sender, dan 4 node berperan sebagai host server storage dari jaringan DSS. Terdapat 20 buah switch yang terdiri dari 4 switch pada core tier, 8 buah switch pada aggregation tier, dan 8 buah switch pada edge tier. Semua switch akan terhubung kepada controller yang berfungsi sebagai control plane dari semua perangkat switch yang terhubung. Topologi akan diimplementasikan menggunakan emulator mininet pada sistem operasi LINUX 16.04 dengan ram sebesar 4Gb dan menggunakan pox controller sebagai SDN controller.

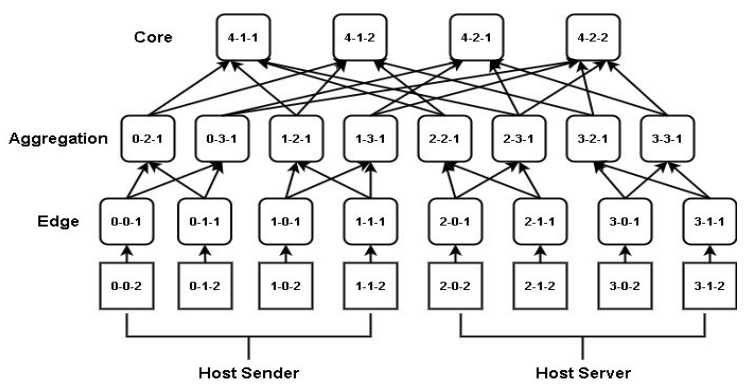

Gambar 2. Topologi Sistem

\subsection{Mekanisme kombinasi server dan link load balancing}

Untuk mekanisme kombinasi server dan link load balancing, akan digunakan fungsi dari Least connection dan fungsi dari global first fit. Diagram alir sistem akan dibagi menjadi dua, pertama adalah diagram yang menunjukkan mekanisme fungsi probe() seperti pada Gambar 3. Pertama, controller akan menginisialisasi switch saat terdapat koneksi dan mengubah status switch menjadi aktif atau "up”. Lalu setelah jumlah total switch sama dengan total switch yang berstatus aktif, akan dijalankan fungsi GetAllPath() yang berfungsi mencatat jalur yang terhubung pada setiap switch serta cost dari setiap jalur, informasi ini akan digunakan untuk menentukan jalur yang terpilih dari algoritme routing. Setelah itu terdapat fungsi probe() untuk mengecek kondisi server menggunakan arp request dan mencatat server yang aktif. Fungsi probe() ini dilakukan berulang kali sampai sistem dimatikan. Jika server membalas arp request, maka server tersebut akan dicatat sebagai server aktif dan diberi waktu timeout untuk selanjutnya akan diproses pada algoritme least connection.

Selanjutnya terdapat mekanisme fungsi utama dari load balancing yang dapat dicermati pada Gambar 4. Fungsi utama pada bagian ini adalah handlepacketin() yang akan berjalan saat terdapat paket yang masuk dari host menuju switch. Dalam sistem ini digunakan jenis routing protocol reactive yaitu proses pencarian jalur routing yang dilakukan jika ada permintaan terlebih dahulu (on-demand). Pada OVS switch paket yang diterima dapat diperoleh alamat sumber dan alamat tujuan.

Saat paket sampai pada switch, maka controller akan mencatat alamat mac dan port tujuan dari node pengirim paket tersebut. Jika alamat mac tujuan merupakan alamat virtual IP yang telah disiapkan, maka akan diproses oleh algoritme least connection untuk dipilihkan satu server dengan koneksi terkecil dari kumpulan server yang aktif. Alamat dari server yang telah terpilih akan diproses oleh algoritme global first fit untuk menentukan jalur yang akan dituju. Jika alamat sumber dari paket yang diterima 
merupakan alamat dari server yang aktif maka paket akan langsung diproses oleh algoritme global first fit untuk ditentukan jalur menuju tujuan. Dari kedua percabangan tersebut akan diproses oleh fungsi installFlow() dan SendFlow() yang berfungsi memasang flow yang ada pada flow table dan mengirim data pada flow yang sudah terpasang. Jika alamat tujuan atau sumber dari paket yang masuk tidak termasuk pada server yang ada, maka akan diteruskan ke semua node untuk mencari node yang mengetahui alamat paket tersebut pada fungsi flood().

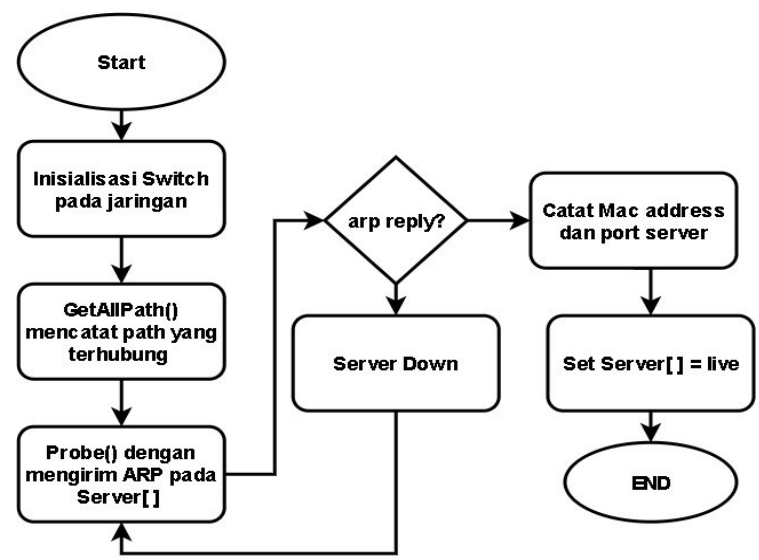

Gambar 3. Diagram alir inisialisasi switch

\subsection{Skenario Pengujian}

Metode evaluasi untuk penelitian ini berbentuk skenario pengujian yang akan dikirim flow dari empat host yang tersedia menuju virtual IP dimana keempat server terhubung. Pengiriman flow berjenis tcp packet menggunakan tools iperf dan dilakukan secara bergiliran dimulai dari host h1 sampai h4 lalu direkam hasilnya pada empat kali iterasi dengan waktu 20 - 50 detik untuk mendapatkan ukuran flow yang mencapai $10 \%$ dari ukuran bandwidth. Secara detail skenario pengiriman adalah sebagai berikut.

- $\quad$ Request berjenis paralel berjumlah 4 dikirim dari H1 menuju VIP selama 20 detik. (flow 1)

- 10 detik setelah flow 1 dimulai, request berjenis paralel berjumlah 2 dikirim dari $\mathrm{H} 2$ menuju VIP selama 30 detik. (flow 2)

Jeda 10 detik dari setiap flow yang dikirim untuk menguji sistem dalam melakukan pemilihan jalur, sedangkan panjang flow sebesar 20-50 detik untuk menguji kinerja algoritme least connection yang bekerja secara efisien jika total koneksi dari server berbeda. Dari skenario pengujian akan diuji parameter throughput, bandwidth, memory usage, dan cpu usage.

- 10 detik setelah flow 2 dimulai, request berjenis paralel berjumlah 2 dikirim dari H3 menuju VIP selama 40 detik. (flow 3)

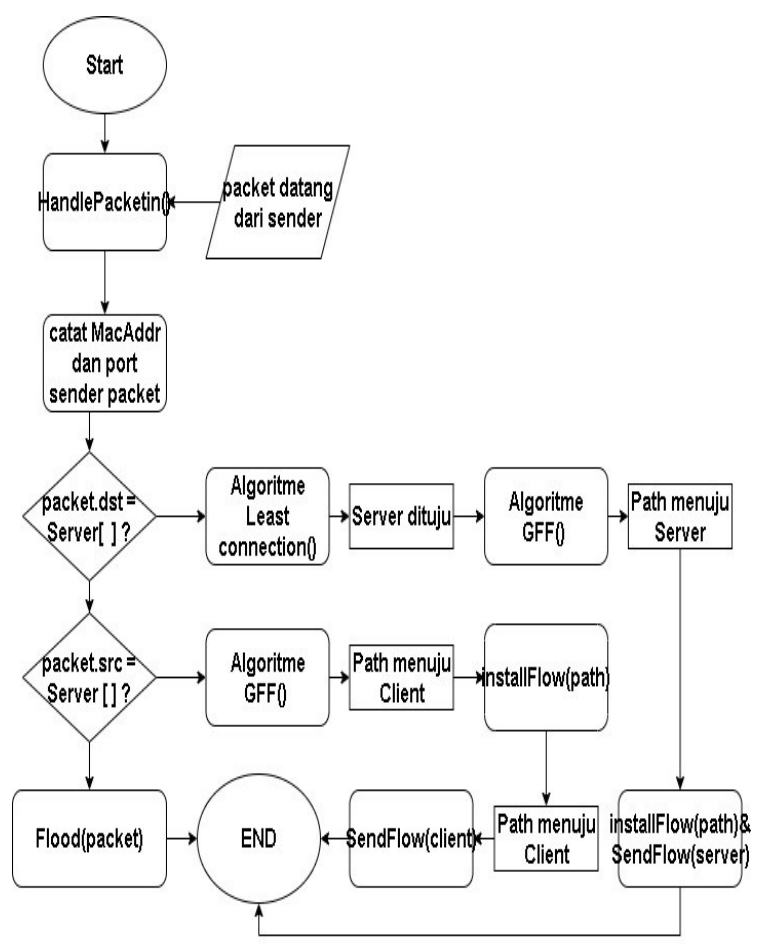

Gambar 4. Diagram alir Load balancing

- 10 detik setelah flow 3 dimulai, request berjenis paralel berjumlah 4 dikirim dari H4 menuju VIP selama 50 detik. (flow 4)

Parameter throughput merupakan rasio yang menunjukkan seberapa banyak jumlah data yang terkirim dari sender ke receiver pada waktu tertentu. Parameter ini adalah salah satu parameter penentu tingginya kinerja dalam kinerja mekanisme load balancing (Wang dkk., 2014). Parameter Bandwidth adalah kapasitas suatu komponen jaringan seperti kabel ethernet yang dilewati oleh trafik paket data dengan jumlah tertentu. Dengan tingginya penggunaan bandwidth pada suatu jaringan menandakan bahwa traffic data sudah di distribusikan secara effisien (Kurose dan Ross, 2007). CPU usage adalah persentase penggunaan prosesor yang digunakan oleh aplikasi. CPU usage diukur berupa persentase dari 0 sampai 100 untuk setiap prosesor yang ada dalam sebuah perangkat. Memory usage adalah persentase penggunaan memory yang digunakan oleh aplikasi. Memory usage diukur berupa persentase dari 0 sampai 100 dari jumlah kapasitas memory yang digunakan.

Hasil pengujian akan dibandingkan dengan algoritme Round-Robin (RR) dan ECMP. Algoritme $\mathrm{RR}$ adalah salah satu jenis algoritme tradisional yang sering dipakai pada metode server load balancing sebagai pembanding dikarenakan menggunakan skema yang sederhana. Cara kerja algoritme ini adalah Flow yang dikirim akan diteruskan ke server yang tersedia satu per satu secara urut (Mahmood dan Rashid, 2011). Algoritme ECMP merupakan algoritme dasar load balancing yang paling banyak 
dipakai dalam jaringan multipath berbasis multi layer seperti DCN. Algoritme ECMP bekerja dengan membagi flow yang akan dikirim menjadi dua flow dengan beban yang sama ketika ada percabangan pada jaringan menggunakan penjadwalan hash atau round robin (Ye dkk., 2018).

\section{HASIL DAN PEMBAHASAN}

\subsection{Throughput \& Packet received}

Hasil dari pengujian throughput didapatkan dari pengujian setiap flow yang ada seperti pada Gambar 5. Host sender diberikan label berdasarkan mac address yang dimiliki dan disederhanakan seperti pada Gambar 2. Keempat host yang

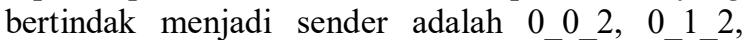
1_0_2, dan 1_1_2. Flow 1 didapat dari pengiriman host 0_0_2, flow 2 didapat dari pengiriman host 012 , dan seterusnya. Hasil yang diperoleh merupakan nilai rata-rata setiap flow dari waktu yang ditentukan. Nilai throughput dari metode yang diajukan mengungguli nilai dari metode $R R+E C M P$. Pada Gambar 6 adalah grafik dari hasil packet received dengan parameter Mbyte. Hasil evaluasi dari rata-rata nilai throughput metode kombinasi adalah $547,5 \mathrm{Mb} / \mathrm{s}$ dan rata-rata byte received sekitar $18,1 \mathrm{~Gb}$ dibanding hasil dari rata-rata throughput metode ECMP dan RR adalah $307,75 \mathrm{Mb} / \mathrm{s}$ dan ratarata byte received sekitar 11,4 Gb. Terdapat peningkatan nilai throughput sebesar 77,9\% dibanding metode ECMP dan RR yang didapat dari perbedaan hasil rata-rata throughput pada metode kombinasi dan metode RR+ECMP. Hasil throughput dan packet received pada flow 1 dan flow 2 lebih tinggi dari pada nilai host lainnya dikarenakan flow pada host 0_0_2 dan 1_1_2 mengirimkan paralel request sejumlah 4, sedangkan host lainnya mengirim paralel request sejumlah 2. Hasil throughput dan packet received dari flow kedua dan ketiga juga turun dikarenakan jalur yang ada digunakan oleh dua atau lebih flow sehingga bandwidth yang digunakan juga akan ikut turun.

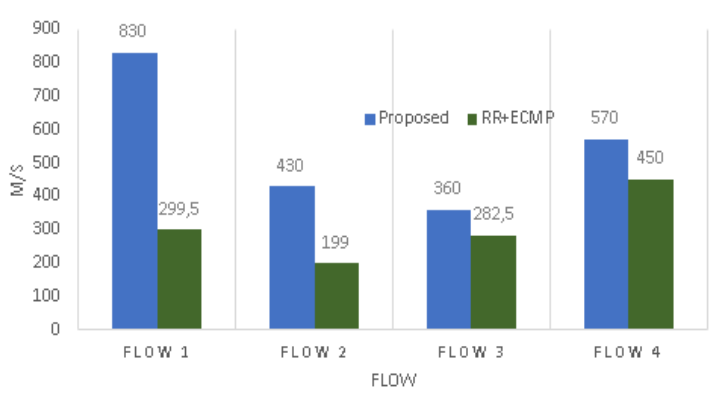

Gambar 5. Grafik hasil Throughput

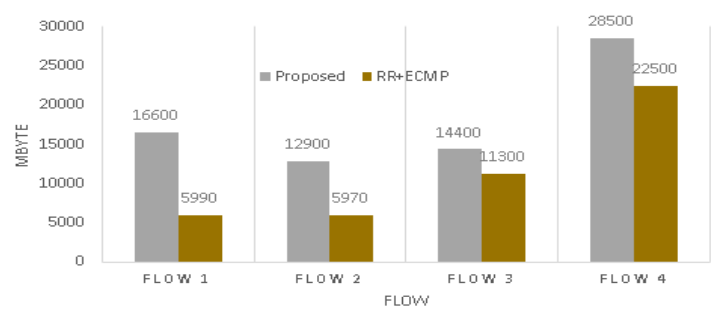

Gambar 6. Grafik hasil Packet received

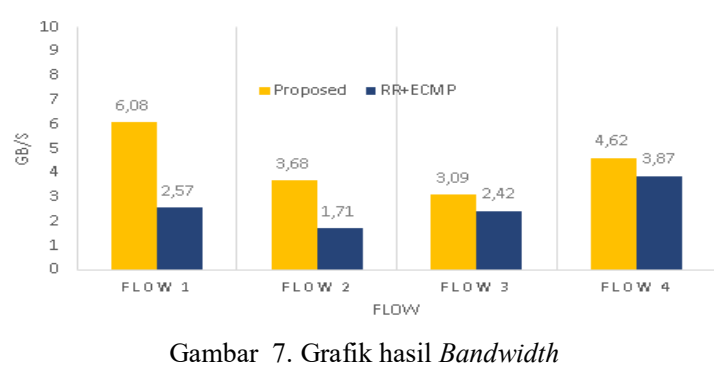

\subsection{Bandwidth}

Pada Gambar 7 adalah grafik hasil penggunaan bandwidth dari semua flow yang diuji. Hasil diperoleh dari rata-rata penggunaan bandwidth setiap flow dari waktu yang ditetapkan di skenario pengujian. Penggunaan bandwidth dari semua flow berhasil mengisi lebih dari $1 \mathrm{~Gb}$ yang merupakan $10 \%$ dari kapasitas bandwidth pada semua jalur, hal ini membuktikan bahwa penggunaan metode global first fit sukses menyeimbangkan traffic data yang berukuran lebih dari 10\% kapasitas bandwidth. Hasil evaluasi dari rata-rata nilai bandwidth metode kombinasi adalah 4,36 Gb/s dibanding hasil dari rata-rata penggunaan bandwidth metode ECMP dan RR adalah 2,64 Gb/s. Dari hasil yang diperoleh terdapat peningkatan sebesar $65,2 \%$ dibanding hasil metode RR+ECMP yang didapat dari perbedaan hasil rata-rata penggunaan bandwidth. Data uji dari pengujian throughput, bandwidth, dan packet received dapat diamati dengan jelas pada Tabel 1 .

Tabel 1. Data hasil pengujian

\begin{tabular}{|c|c|c|c|c|c|c|}
\hline Node & $\begin{array}{l}\text { Detik } \\
\text { (w) }\end{array}$ & paralel & $\begin{array}{l}\text { jumlah } \\
\text { packet }\end{array}$ & $\begin{array}{l}\text { BW } \\
(\mathrm{Gb} / \mathbf{s})\end{array}$ & $\begin{array}{l}\text { Tgpt } \\
(\mathbf{M b} / \mathbf{s})\end{array}$ & \\
\hline 0_0_2 & 20 & 4 & 16600 & 6,08 & 830 & \multirow{4}{*}{$\begin{array}{l}\text { D् } \\
0 \\
0 \\
0 \\
0\end{array}$} \\
\hline 0_1_2 & 30 & 2 & 12900 & 3,68 & 430 & \\
\hline 1_0_2 & 40 & 2 & 14400 & 3,09 & 360 & \\
\hline 1_1_2 & 50 & 4 & 28500 & 4,62 & 570 & \\
\hline 0_0_2 & 20 & 4 & 5990 & 2,57 & 299,5 & \\
\hline 0_1_2 & 30 & 2 & 5970 & 1,71 & 199 & $\sum$ \\
\hline 1_0_2 & 40 & 2 & 11300 & 2,42 & 282,5 & \\
\hline 1_1_2 & 50 & 4 & 22500 & 3,87 & 450 & \\
\hline
\end{tabular}

\subsection{CPU dan Memory Usage}

Parameter pengujian terakhir yaitu memory usage dan CPU usage. Hasil dari pengujian memory usage seperti pada Gambar 8. Satuan yang digunakan adalah persentase (\%) dari pemakaian 
memory swap+RAM dari total $100 \%$ kapasitas memory yang ada. Rata-rata penggunaan memory dari metode yang diajukan adalah $53,86 \%$ dan ratarata penggunaan ECMP+RR adalah $59,15 \%$. Dari hasil memory usage metode yang diajukan terdapat penurunan sebesar 9,81\% dibanding hasil metode ECMP+RR. Kedua metode yang diuji juga menghasilkan penggunaan memory yang seimbang untuk setiap server. Hal ini membuktikan bahwa kedua metode dapat mengatur beban pada server dengan seimbang.

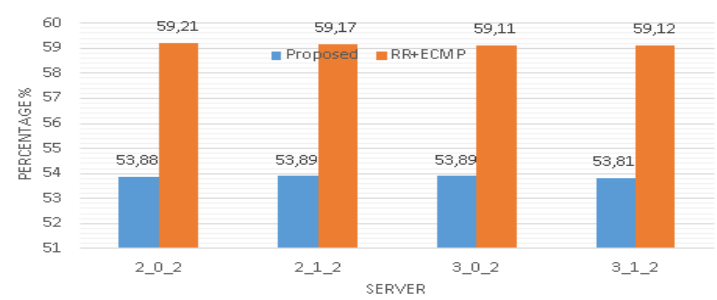

Gambar 8. Grafik hasil memory usage

Untuk pengujian CPU usage digunakan persentase penggunaan user, sys, dan idle. User adalah penggunaan CPU pada aplikasi yang berjalan pada user tertentu, sys yaitu penggunaan CPU yang berjalan pada sistem kernel, dan idle yaitu CPU yang tidak digunakan. Total persentase dari ketiga parameter tersebut yaitu $100 \%$. Hasil dari pengujian CPU usage pada metode yang diajukan dapat diamati pada Gambar 9. Persentase rata-rata dari user yaitu $10,08 \%$, pada sys $83,78 \%$, dan pada idle $6,13 \%$. Sedangkan hasil dari pengujian cpu usage pada metode RR+ECMP dapat diamati pada Gambar 10, dengan hasil persentase dari parameter user sekitar $13,54 \%$, pada sys sekitar $81,5 \%$, dan pada idle yaitu $5,13 \%$. Dari hasil rata-rata penggunaan CPU usage terjadi penurunan beban CPU sebesar $34,29 \%$ pada user CPU dibanding hasil metode ECMP+RR. Hasil yang didapat dari kedua metode dapat diketahui bahwa hampir semua kapasitas CPU (80\%) digunakan.

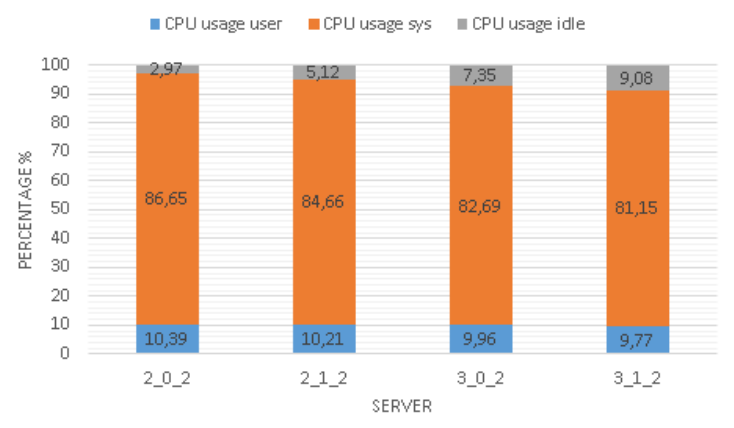

Gambar 9. Grafik hasil proposed cpu usage

\section{KESIMPULAN}

Penelitian ini mengajukan metode kombinasi link dan server load balancing pada jaringan DSS guna meningkatkan utilisasi jaringan. Penerapan metode kombinasi yang diajukan berhasil meningkatan nilai throughput rata-rata $77 \%$ lebih tinggi dari hasil metode ECMP.

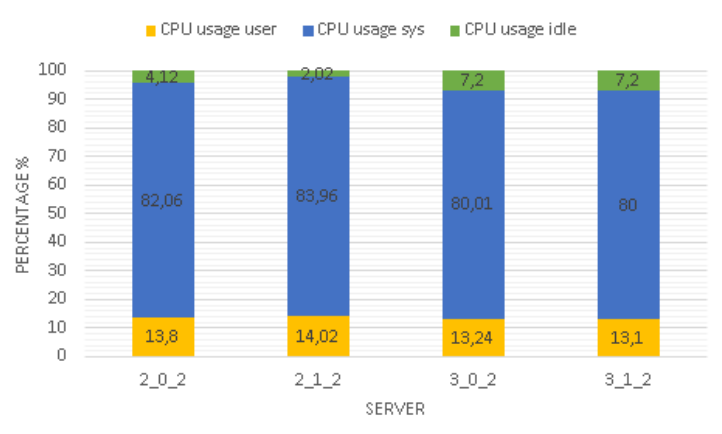

Gambar 10. Grafik hasil rr+ecmp cpu usage

Pengujian penggunaan bandwidth menunjukkan peningkatan dengan rata-rata $65 \%$ lebih tinggi dari hasil metode ECMP. Penggunaan bandwidth dari kedua metode berhasil mengisi lebih dari $1 \mathrm{~Gb}$ yang merupakan $10 \%$ dari kapasitas bandwidth pada semua jalur, hal ini membuktikan bahwa penggunaan metode global first fit sukses mengatur traffic data yang berukuran lebih dari $10 \%$ kapasitas bandwidth. Hasil Penggunaan cpu dan memory pada server di metode kombinasi ini juga terjadi penurunan beban сри sebesar $34,2 \%$ dan penurunan beban penggunaan memory sebesar 9,81\% dibanding metode ECMP dan RR meskipun pembagian penggunaan cpu dan memory dari kedua metode seimbang. Dengan demikian algoritme global first fit dengan sukses mendeteksi adanya bottleneck pada jaringan dan menyeimbangkan traffic ke semua jalur yang ada. Dari hasil evaluasi, penerapan metode kombinasi metode server dan link load balancing berhasil meningkatkan utilisasi jaringan dan juga mengurangi beban server.

\section{DAFTAR PUSTAKA}

AL-FARES, M., RADHAKRISHNAN, S., RAGHAVAN, B., HUANG, N., DAN VAHDAT, A. (2010): Hedera, Hedera: Dynamic Flow Scheduling for Data Center Network,130-131. https://doi.org/10.1201/b16160-86

CHEN, W., LI, H., MA, Q., DAN SHANG, Z. (2014): Design and implementation of server cluster dynamic load balancing in virtualization environment based on OpenFlow, ACM International Conference Proceeding Series, 2014-May(May), 691-697. https://doi.org/10.1145/2619287.2619288

DIMAKIS, A. G., GODFREY, P. B., WU, Y., WAINWRIGHT, M. J., DAN RAMCHANDRAN, K. (2010): Network coding for distributed storage systems, IEEE Transactions on Information Theory, 56(9), 4539-4551. https://doi.org/10.1109/TIT.2010.2054295

FLEXERA (2020): 2020 Flexera State of the Cloud Report, 1-19. 
GUILLEN, L., IZUMI, S., ABE, T., SUGANUMA, T., DAN MURAOKA, H. (2018a): SDNbased hybrid server and link load balancing in multipath distributed storage systems, IEEE/IFIP Network Operations and Management Symposium: Cognitive Management in a Cyber World, NOMS 2018, 1-6. https://doi.org/10.1109/NOMS.2018.8406286

GUILLEN, L., IZUMI, S., ABE, T., SUGANUMA, T., DAN MURAOKA, H. (2018b): SDN implementation of multipath discovery to improve network performance in distributed storage systems, 2017 13th International Conference on Network and Service Management, CNSM 2017, 2018-January, 1-4. https://doi.org/10.23919/CNSM.2017.8256054

KANEKO, S., NAKAMURA, T., KAMEI, H., DAN MURAOKA, H. (2016): A guideline for data placement in heterogeneous distributed storage systems, Proceedings - 2016 5th IIAI International Congress on Advanced Applied Informatics, IIAI-AAI 2016, (disk M), 942945.https://doi.org/10.1109/IIAIAAI.2016.162

KREUTZ, D., RAMOS, F. M. V., VERISSIMO, P. E., ROTHENBERG, C. E., AZODOLMOLKY, S., DAN UHLIG, S. (2015): Software-defined networking: A comprehensive survey, Proceedings of the IEEE, 103(1), 14-76.

https://doi.org/10.1109/JPROC.2014.2371999

KUROSE, J., DAN ROSS, K. (2007): Chapter 1 : Introduction Chapter 1 Background Chapter 1 : roadmap "Cool" internet appliances What 's a protocol?, 1-20.

LIU, Y., RAMESHAN, N., MONTE, E., VLASSOV, V., DAN NAVARRO, L. (2015): ProRenaTa: Proactive and reactive tuning to scale a distributed storage system, Proceedings - 2015 IEEE/ACM 15th International Symposium on Cluster, Cloud, and Grid Computing, CCGrid 2015, 453-464. https://doi.org/10.1109/CCGrid.2015.26

MAHMOOD, A., DAN RASHID, I. (2011): Comparison of load balancing algorithms for clustered web servers, 2011 International Conference on Information Technology and Multimedia: "Ubiquitous ICT for Sustainable and Green Living”, ICIM 2011, (November). https://doi.org/10.1109/ICIMU.2011.6122721

MUSTAFA, M. E. (2017): Load Balancing Algorithms Round-Robin ( $\mathrm{Rr}$ ), LeastConnection, and Least Loaded Efficiency, Computer Science and Telecommunications, diperoleh melalui situs internet: http://gesj.internetacademy.org.ge/download.p hp? $\mathrm{id}=2886$. pdf\&t=1, 51(1), 25-29.
SUH, C., DAN RAMCHANDRAN, K. (2011): Exact-Repair MDS Code Construction Using, 57(3), 1425-1442.

WANG, T., SU, Z., XIA, Y., DAN HAMDI, M. (2014): Rethinking the data center networking: Architecture, network protocols, and resource sharing, IEEE Access, 2, 1481-1496. https://doi.org/10.1109/ACCESS.2014.238343 9

XIA, W., WEN, Y., DAN FOH, C. H. (2018): A Survey on Software-Defined Networking, Asian Pacific Journal of Reproduction, 7(2), 72-78. https://doi.org/10.4103/23050500.228016

YE, J. L., CHEN, C., DAN HUANG CHU, Y. (2018): A Weighted ECMP Load Balancing Scheme for Data Centers Using P4 Switches, Proceedings of the 2018 IEEE 7th International Conference on Cloud Networking, CloudNet 2018, 1-4. https://doi.org/10.1109/CloudNet.2018.854954 9

ZHANG, J., YU, F. R., WANG, S., HUANG, T., LIU, Z., DAN LIU, Y. (2018): Load balancing in data center networks: A survey, IEEE Communications Surveys and Tutorials, 20(3), 2324-2325. https://doi.org/10.1109/COMST.2018.281604 2 
Halaman ini sengaja dikosongkan 